\title{
La regalía minera en Ecuador: ¿un recurso patrimonial originario con apariencia de tributo?
}

\author{
María del Carmen Crespo Alvear*
}

\section{RESUMEN}

Al ser aceptado que todos los Estados necesitan ingresos para cumplir sus fines, resulta pertinente preguntarse de dónde provienen esos ingresos o con qué medios cuentan los Estados para poder obtenerlos. En el caso ecuatoriano, a partir del año 2008, se ha considerado recurrir a la explotación de minerales mediante la industrialización de la actividad minera para obtener ingresos. Los minerales son de titularidad y de dominio exclusivo del Estado, pero se permite que particulares coparticipen del aprovechamiento de esa actividad mediante el pago de tributos, regalías, patentes y utilidades laborales atribuibles al Estado.

Con relación a la regalía minera, la discusión gira entorno a si es un tributo, o si se trata de un recurso patrimonial originario fundado en un derecho de propiedad atribuible al Estado. Frente a esta interrogante, y la importancia económica que representa la actividad minera, se realiza un análisis de la figura a la luz de la teoría de las finanzas públicas. Se concluye que en Ecuador existe una posición ambigua entre las dos figuras, lo que genera graves conflictos jurídicos y económicos.

PALABRAS CLAVE: regalía minera; tributo; recurso público; régimen fiscal, ingresos, minería.

\section{ABSTRACT}

It is well established that all States need income in order to fulfill their duties, that is why it is relevant to ask where do this income originates from, or with what means do States count in order to obtain it. In the Ecuadorian case, since 2008, exploiting minerals has been considered a viable option to secure income through industrialization of mining activities. Minerals are exclusively owned by the State; however, private parties may co-participate in the benefits of this activity while paying taxes, royalties, patents, and labor profits to the State.

* Estudiante de la maestría en Tributación, Georgetown University. 
In regards to the mining royalty, the discussion is centered on whether it is a form of tax, or an original patrimonial resource, based on a property right to which the State is the rightholder. This question, considering the economic importance of mining activities, requires an analysis under the light of the public finance theory. In conclusion, in Ecuador presents an ambiguous position between those two concepts, which creates legal and economic disputes.

KEYWORDS: mining royalty; tax; public resource; fiscal regimen, income, mining.

\section{INTRODUCCIÓN E IMPORTANCIA DE LA ACTIVIDAD MINERA}

$\mathrm{L}$ os Estados, al no contar con un empleo para generar ingresos, cuentan con otros recursos que le permiten obtener liquidez. Dependiendo del Estado en cuestión, y luego de analizar los recursos públicos con los que cuenta, la mayoría opta por la recaudación fiscal o el endeudamiento público, mientras que otros $-\mathrm{y}$ no de forma excluyente- deciden explotar sus recursos naturales.

Con relación al caso ecuatoriano, su mayor fuente de ingresos se encuentra en la explotación de recursos naturales y en la recaudación de tributos. Con el advenimiento de la Constitución más reciente, en concordancia con el Plan Nacional para el Buen Vivir, el Ecuador ha manifestado su intención de cambiar su matriz productiva con el fin de disminuir la dependencia en la explotación petrolera. Para cumplir con este postulado - paradójicamente, a pesar del reconocimiento de los derechos de la naturaleza realizado por parte del Estado ecuatoriano-, ${ }^{1}$ este ha decidido recurrir a otro de sus recursos naturales no renovables a través de la industrialización de la actividad minera. ${ }^{2}$

1. Constitución de la República del Ecuador (2008), tít. II, "Derechos", cap. séptimo, "Derechos de la Naturaleza", art. 71. En adelante se la denominará como Carta Magna o la Constitución. A partir de su aprobación en el año 2008 se transformó no solo la organización del Estado, sino entre las tantas innovaciones introducidas, una que las que más se ha llevado a debate son los denominados derechos de la naturaleza. Bajo este postulado se ha reconocido a la naturaleza o a la Pacha Mama como un sujeto de derechos, otorgándole así un estatus jurídico distinto al que se le venía dando. En el presente ensayo no se hará alusión al análisis de los efectos del mencionado reconocimiento y la minería, al no ser el objeto de la investigación.

2. Secretaría Nacional de Planificación, Plan Nacional para el Buen Vivir 2013-2017. Disponible en 〈http://www. buenvivir.gob.ec/objetivo-11.-asegurar-la-soberania-y-eficiencia-de-los-sectores-estrategicos-para-la-transformacion-industrial-y-tecnologica\#tabs2〉. Objetivo 11.2: Uno de los objetivos primordiales del Estado ecuatoriano es: "industrializar la actividad minera como eje de la transformación de la matriz productiva, en el marco de la gestión estratégica, sostenible, eficiente, soberana, socialmente justa y ambientalmente sustentable". 
La importancia que tienen los minerales en el desarrollo de las actividades humanas, así como en el desarrollo económico de los estados, ha sido reconocida en diversas declaraciones internacionales. ${ }^{3}$ No obstante, el hecho de contar con recursos minerales no equivale necesariamente al desarrollo económico de un Estado, siendo un ejemplo de ello los casos de Zambia y Nambia, países que solamente se han limitado a esperar participaciones y rentas estatales provenientes de la explotación minera, por lo que esa pasividad ha significado poca industrialización y un bajo desarrollo de su economía; caso diametralmente opuesto al chileno, en donde el sector minero ha impulsado fuertemente su crecimiento económico. ${ }^{4}$

Para que la explotación minera pueda alcanzar niveles de éxito que permitan avances en el ámbito social y económico, se requiere no solo de la existencia de yacimientos suficientes, sino de otros componentes como: instituciones públicas comprometidas con el servicio público, políticas públicas idóneas y un marco jurídico que denote seguridad jurídica para inversionistas.

Con relación a "los principios relativos a la propiedad de las minas [estos] han variado con los tiempos y los pueblos", ${ }^{5}$ siendo esta una de las razones por la que existen diversas teorías acerca del dominio de los minerales; las que han tomado elementos tanto del derecho civil como del derecho público, y han estructurado distintos

3. Declaración de Río+20 de la Conferencia de las Naciones Unidas sobre el Desarrollo Sostenible (2012) 227-8. Reconocemos que los minerales y los metales hacen una gran contribución a la economía mundial y las sociedades modernas. Observamos que las industrias mineras son importantes para todos los países con recursos minerales, en particular los países en desarrollo. También observamos que la minería ofrece la oportunidad de catalizar un desarrollo económico de amplia base, reducir la pobreza y ayudar a los países a lograr los objetivos de desarrollo convenidos internacionalmente, entre ellos los Objetivos de Desarrollo del Milenio, cuando se gestiona de manera efectiva y adecuada. Reconocemos que los países tienen el derecho soberano a explotar sus recursos minerales de conformidad con sus prioridades nacionales y la responsabilidad sobre la explotación de los recursos que se describe en los Principios de Río. Reconocemos también que las actividades mineras deben aumentar al máximo los beneficios sociales y económicos y abordar de manera efectiva los efectos negativos ambientales y sociales. En este sentido, reconocemos que los gobiernos necesitan una gran capacidad para desarrollar, gestionar y reglamentar sus industrias mineras en interés del desarrollo sostenible. [...] Exhortamos a los gobiernos y las empresas a que promuevan un aumento continuo de la rendición de cuentas y la transparencia, así como la eficacia de los mecanismos existentes pertinentes para prevenir las corrientes financieras ilícitas derivadas de actividades mineras.

4. Guilherme Lima de Moura, "La administración de los bienes minerales como fuerza motriz del desarrollo social”, Foro: Revista de Derecho, No. 21 (2014): 67.

5. Ramón Parada, Derecho administrativo III: Bienes públicos; Derecho urbanístico (Madrid: Marcial Pons, 2013), 199. 
sistemas de regulación. ${ }^{6}$ Algunos países como Bolivia, ${ }^{7}$ Chile, ${ }^{8}$ Brasil ${ }^{9}$ y Ecuador ${ }^{10}$ han adoptado un régimen dominical y han determinado que los recursos naturales no renovables son bienes de propiedad exclusiva del Estado. No obstante, la titularidad de dominio de los minerales no excluye per se la participación de particulares; ya que, en virtud de la especificidad de la actividad minera, los altos costos y el riesgo que conlleva la exploración y explotación de minerales, no resulta eficiente ni recomendable que los Estados inviertan ingresos públicos en esta actividad, siendo preferible que se otorguen concesiones a particulares, conservando los Estados el ejercicio de las facultades de regulación y control.

Con relación específica al caso ecuatoriano, si bien por disposiciones constitucionales se ha determinado que el Estado central tendrá competencia exclusiva sobre los recursos minerales, se permite que el sector privado coparticipe de su aprovechamiento. A través de normativa secundaria en materia minera se han establecido los procedimientos, estableciendo principalmente que la coparticipación se realice mediante el pago de tributos, regalías, patentes y utilidades laborales atribuibles al Estado ecuatoriano.

De estas cuatro formas de coparticipación, cada una merece un análisis profundo, considerando que la claridad conceptual de cada figura permite una regulación normativa correcta. No obstante, el enfoque de este estudio es la regalía minera y busca dar respuesta práctica y doctrinaria a la interrogante planteada de si esta se trata de un tributo y en particular de un impuesto, o bien se trata de un recurso originario fundado en un derecho de propiedad que el Estado tiene sobre los minerales existentes en el subsuelo de su territorio. ${ }^{11}$

\section{DEFINICIÓN DE RECURSO PÚBLICO}

En la cotidianeidad de las relaciones interpersonales se utilizan de manera indistinta las frases carente de recursos o carente de ingresos para referirse al hecho de caren-

\footnotetext{
6. Víctor del Barco Carrillo, Tributación minera (La Paz: Azul, 2006), 17.

7. Constitución Política del Estado Plurinacional de Bolivia (2009), tercera parte, tít. II, cap. segundo, "Recursos naturales", art. 348-358.

8. Constitución de Política de la República de Chile (1980), cap. tercero, "De los derechos y derechos constituciones", art. 19, numeral 24.

9. Constitución de la República Federativa de Brasil (1998), tít.VI, cap. primero, "De los principios generales de actividad económica", art. 176.

10. Constitución de la República del Ecuador (2008), tít. VII, "Régimen del Buen Vivir", cap. segundo, "Biodiversidad y recursos naturales", art. 408.

11. Dino Jarach, Finanzas públicas y Derecho tributario, 3a. ed. (Buenos Aires: Abeledo Perrot, 1996), 254.
} 
cia económica. Esta asimilación de términos, que para la mayoría de personas puede no tener mayores connotaciones, en el contexto jurídico cobra mayor relevancia, por lo que la falta de precisión terminológica acarrea varias controversias tanto de índole doctrinaria como pecuniaria.

Por razones de precisión académica es relevante hacer las siguientes aclaraciones del término recurso público, considerándolo dentro del ámbito de las finanzas públicas, específicamente en el área de estudio del derecho financiero público, teniendo en cuenta que dicha área "pertenece al derecho público y se constituye por el conjunto de normas que disciplinan los recursos públicos, la gestión, y la consecuente erogación de los mismos". ${ }^{2}$

Con esta puntualización, se debe partir del hecho de que todos los Estados obtienen los mismos ingresos, entendidos de manera general como todo flujo monetario de la tesorería del Estado. Para el autor Valdés Costa, "los ingresos financieros son las entradas en la tesorería del Estado para el cumplimiento de sus fines, cualquiera sea su naturaleza económica o jurídica". ${ }^{13}$ Sin embargo, no todos los Estados cuentan con los mismos medios para obtener ingresos, es decir, no cuentan con los mismos recursos. Si bien varios autores ${ }^{14}$-al igual que en las relaciones interpersonales- asimilan los términos ingresos públicos del Estado con recursos públicos, esto es parcialmente incorrecto, por lo que en este trabajo se adoptará un concepto a partir de las definiciones planteados por autores que sí realizan una diferenciación.

Villegas define los recursos públicos como "aquellas riquezas que se devengan a favor del Estado para cumplir sus fines y que en tal carácter ingresan en su tesorería". ${ }^{15}$ Por otra parte, Falcón Tella menciona que "son institutos jurídicos, es decir un conjunto de normas configuradas de modo unitario sobre la base [de] una idea organizativa común". ${ }^{16}$ Jarach establece que constituyen recursos del Estado "los procedimientos mediante los cuales el mismo logra poder de compra necesario para efectuar las erogaciones propias de la actividad financiera". ${ }^{17}$

De las definiciones planteadas, se concluye que los recursos públicos son instituciones -jurídicas o con connotación jurídica- que, a partir de un procedimiento determinado, ingresan al tesoro del Estado, y la riqueza que representan sirve para que

12. José Vicente Troya, "De la actividad finanaciera y las ciencias que ellas tratan", en Manual de Derecho tributario (Quito: Documento actualizado a agosto 2011 en versión digital sin publicar, 1997), 13.

13. Ramón Valdés Costa, Curso de Derecho tributario (Bogotá: Temis, 1996), 1.

14. Véase en Villegas, Manual de finanzas públicas (Buenos Aires: Depalma, 2000), 153-5.

15. Ibíd., 155.

16. Ramón Falcón Tella, Derecho financiero y tributario (parte general) (Madrid: Universidad Complutense de Madrid, 2013), 18.

17. Jarach, Finanzas públicas y Derecho tributario, 221. 
este pueda cumplir sus fines. En este sentido "mientras que [el recurso] se compone de todas las fuentes para efectos de solventar el gasto público; los ingresos propiamente dichos son las efectivas recaudaciones, aquellas entradas que siendo parte o no del prepuesto se acreditaron a cuenta del Estado para satisfacer necesidades públicas". ${ }^{18}$

Así, dependiendo de los tipos de recursos públicos, los cuales de manera potencial representan la posibilidad de un ingreso futuro, deberá el Estado determinar cuál es el que requiere para obtener de manera real -o percibida- una suma de dinero que ingrese a su tesorería y le permita financiar sus gastos. Bajo estas razones es que previamente se mencionó que el asimilar recurso con ingreso es parcialmente incorrecto debido a que a un recurso se lo pudiera considerar como un ingreso futuro en potencia.

Puntualizado el concepto de recurso público, antes de continuar con la clasificación de los recursos públicos en donde se encasillará a la regalía minera, vale recalcar que los recursos con los que cuentan los Estados son diversos. Entre ellos se puede mencionar: 1. recursos patrimoniales, pudiendo subclasificarse en recurso natural no renovable, recurso natural renovable, patrimonio público de uso privado (renta mobiliaria e inmobiliaria); 2. poder tributario, en donde se hace alusión a recursos tributarios; 3. poder financiero, como los precios públicos; 4. poder crediticio; 5. poder monetario; y 6. poder sancionatorio. ${ }^{19}$

De todos estos recursos, cada Estado tiene la potestad de determinar a cuál recurre para obtener los ingresos que deberán utilizarse según sus previsiones en un presupuesto general que detalle correlativamente los gastos públicos. Al ser recursos con los que ya cuenta el Estado, los funcionarios públicos solamente encontrarán limitaciones para su utilización en la normativa interna, especialmente en las constituciones de cada país.

Es importante comprender qué se entiende por recurso público, ya que permite diferenciarlo no solo del ingreso, sino también del gasto público, siendo "el proceso de determinación de ambos [gastos/recursos] muy complejo y se desarrolla a través de cotejos múltiples de utilidades y sacrificios: o sea, utilidades y [sic. desutilidades] según el método de comparaciones marginales de acuerdo con las escalas de prioridades de gastos y recursos" ${ }^{20}$ La complejidad y tecnicidad del proceso requiere un alto grado de especificidad que busca no solo brindar servicios públicos y satisfacer necesidades apremiantes, sino también alcanzar eficiencia en la utilización de recursos que en su mayoría son escasos.

\footnotetext{
18. Ibíd., 33.

19. Ibíd., 221.

20. Ibíd., 221.
} 


\section{CLASIFICACIÓN DE LOS RECURSOS PÚBLICOS}

Delimitado el concepto de recurso público, resulta relevante analizar su clasificación, con el objetivo de conocer cuál es el que da origen al cobro de una regalía minera. Autores como Jarach, ${ }^{21}$ Villegas ${ }^{22}$ y Ahumada ${ }^{23}$ coinciden en que no es posible realizar una sola tabla en la que se incluyan todas las clasificaciones de recursos públicos posibles. No obstante, mencionan que de manera didáctica se pueden englobar ciertos tipos de recursos por categorías con el fin de resolver cuestiones de hecho en relación a las semejanzas y diferencias de cada uno.

Del sin número de clasificaciones que existen, por la pertinencia para este trabajo, se analizará la clasificación de los recursos por el origen de la fuente económica, ${ }^{24}$ encontrándose recursos originarios [3.1] y recursos derivados [3.2]. Para concluir esta sección se hará mención a los límites de separación entre los recursos patrimoniales originarios y los recursos derivados tributarios con relación a la regalía minera [3.3].

\section{RECURSOS ORIGINARIOS}

El Estado cuenta con recursos originarios que "provienen de los bienes patrimoniales del Estado o de diversos tipos de actividades productivas realizadas por este". ${ }^{25}$ En necesario mencionar que "dentro del concepto de patrimonio público, a diferencia del patrimonio privado, no se incluye el dinero, ni los créditos derivados de otros recursos de la Hacienda pública". ${ }^{26}$ Se denominan originarios porque los bienes le pertenecen al Estado, o los servicios son prestados por él a cambio de un precio.

Dentro del primer grupo se hace referencia al patrimonio del Estado, y son los recursos que permitirán obtener ingresos a consecuencia de su aprovechamiento económico. ${ }^{27}$ En esta categoría se encuentran: a) los recursos naturales no renovables como yacimientos mineros o hidrocarburíficos, los cuales generan ingresos a consecuencia de su explotación; b) los recursos naturales renovables como exportaciones de productos agrícolas; c) el patrimonio público de uso privado de renta mobiliaria o

21. Ibíd., 221-2.

22. Villegas, Manual de finanzas públicas, 161.

23. Guillermo Ahumada, Tratado de finanzas públicas, t. I, 4a. ed. (Buenos Aires: Plus Ultra, 1968), 184.

24. "La clasificación de recursos originarios y derivados se identifica parcialmente con la clasificación de los recursos patrimoniales y tributarios", por lo que ciertas características de esa categoría serán incluidas en la clasificación utilizada en este trabajo. Jarach, Finanzas públicas y Derecho tributario, 223.

25. Villegas, Manual de finanzas públicas, 162.

26. Falcón Tella, Derecho financiero y tributario (parte general), 19.

27. Jarach, Finanzas públicas y Derecho tributario, 225. 
de renta inmobiliaria, mediante el pago al Estado de un precio por el que puede vender -casos excepcionales- o regular su utilización (siempre que la legislación lo permita).

Con relación al segundo grupo, el Estado puede recibir ingresos a consecuencia de la prestación de servicios por parte de una empresa pública, o mixta. ${ }^{28}$ Dentro de las rentas inmobiliarias provenientes de patrimonio público de uso privado. Autores como Villegas, hacen mención a "las rentas provenientes de bienes que el Estado conserva en propiedad como por ejemplo, arrendamiento de tierras públicas, explotación de bosques, concesión minera". ${ }^{29}$

\section{RECURSOS DERIVAdos}

Los recursos derivados "son aquellos que las entidades públicas procuran mediante contribuciones provenientes de las economías de los individuos pertenecientes a la comunidad" 30 o que "son extraídos del patrimonio ajeno por el poder de imperio del Estado". ${ }^{31}$ En esta categoría suele incluirse a los recursos del poder tributario y crédito, $\mathrm{y}$, en ciertos casos, del poder sancionatorio.

Algunos autores incluyen los recursos crediticios en razón de que, para que el Estado pueda cumplir con el pago de intereses y amortizaciones adeudadas, debe recurrir a su poder tributario para recaudar fondos. Por otra parte, de los rubros que se recaudan en virtud de la facultad sancionadora parece no haber acuerdo de si provienen o no de un recurso. Para autores como Falcón Tella el régimen de infracción no puede considerarse como recurso, ya que la finalidad de la sanción no es el obtener ingresos. ${ }^{32}$ Por el contrario, el doctrinario Ahumada incluye las multas y las penalidades dentro de los recursos derivados, y comenta que "no solo las leyes tributarias contienen sanciones pecuniarias penales; la inobservancia de muchas otras disposiciones formales o de fondo, pueden traducirse también en sanciones de carácter pecuniario y representan desde este punto de vista la sanción, un recurso fiscal". ${ }^{33}$

La inclusión de los recursos tributarios en esta categoría cuenta con absoluto acuerdo doctrinario y constituye la mayor fuente de ingresos de los Estados. Se los define como "recursos (conjunto de normas) que delimitan o definen un presupuesto de hecho, normalmente demostrativo de capacidad económica, cuya realización origi-

28. La efectividad del cobro de este precio público es discutido por la compatibilidad que puede o no darse entre la finalidad de las empresas -lucro-y la prestación de un servicio público.

29. Villegas, Manual de finanzas públicas, 167.

30. Ibíd., 162.

31. Jarach, Finanzas públicas y Derecho tributario, 223.

32. Falcón Tella, Derecho financiero y tributario (parte general), 17.

33. Ahumada, Tratado de finanzas públicas, 216. 
na una obligación de dar dinero [preferiblemente] con la finalidad de cubrir los gastos públicos". ${ }^{34}$ Las figuras clásicas que se desprenden de los recursos tributarios como subcategorías son: impuestos, tasas y contribuciones especiales; no obstante el autor Jarach también incluye a los empréstitos forzosos, los recursos parafiscales, y las regalías del sector público, debido a que a su criterio, en ellos también se destaca un fin público y el carácter coercitivo del Estado. ${ }^{35}$ Con relación a las tres últimas figuras existe aún debate si se las debe o no considerar tributos.

\section{LÍMITES DE SEPARACIÓN ENTRE LOS RECURSOS PATRIMONIALES ORIGINARIOS Y LOS RECURSOS DERIVADOS TRIBUTARIOS CON RELACIÓN A LA REGALÍA MINERA}

Si bien la regalía minera representa un ingreso público, y consiste en una erogación que se realiza al Estado, en este acápite se denota la tensión que existe entre lo que algunos consideran un recurso público patrimonial originario, y lo que para otros debería ser un recurso derivado como el tributo. Mientras que la obligación de pago de un tributo surge solamente a consecuencia del cumplimiento de un mandato legal, para cierto grupo de autores la obligación de pago de una regalía, al ser una contraprestación o compensación, se produce como resultado de la celebración de un contrato, por lo que la relación entre el Estado y el particular se rige por una normativa distinta a la del derecho tributario.

Las actividades que generan ingresos por medio de los recursos patrimoniales originarios y los recursos tributarios suelen diferir ampliamente, por lo que cada categoría debería tener una regulación propia. Lo ideal sería que, una vez identificado claramente el tipo de recurso, los Estados adopten la regulación adecuada dependiendo de la categorización que le otorguen; sin embargo, la regulación no siempre es armónica ni sistemática. Un ejemplo claro de esta problemática se evidencia en la figura de la regalía minera.

Algunos Estados, así como cierta parte de la doctrina, entienden la regalía minera como un derecho, y la definen como la "utilización o explotación que una empresa hace de una patente, técnica u obra que son propiedad de un tercero, derivada de la autorización contractual que este le hace y por la que se paga una suma de dinero". ${ }^{36}$ La característica fundamental que es resaltada por esta corriente doctrinaria es la na-

34. Falcón Tella, Derecho financiero y tributario (parte general), 18.

35. Jarach, Finanzas públicas y Derecho tributario, 235.

36. Fernando Martino Mendiluce, Diccionario de conceptos económicos y financieros (Santiago de Chile: Andrés Bello, 2001), 244. Citado en Pablo Valderrama, "En torno al debate sobre la aplicación de un royalty o renta 
turaleza contra-prestacional o contractual de la regalía minera, en donde se reconoce el derecho de cobro por parte del Estado, pero no por asimilarla a un tributo. El autor Vega menciona que "el royalty es un derecho que el Estado soberano cobra al concesionario por la explotación de sus riquezas naturales". ${ }^{37}$

La Sala Plena de la Corte Constitucional de Colombiana, en el caso C-207/00 del 1 de marzo de 2000, también se pronunció acerca de una regalía minera, y, concentrándose en el destino de la misma, determinó que "las regalías son ingresos públicos pero no tienen naturaleza tributaria, pues no son imposiciones del Estado sino contraprestaciones que el particular debe pagar por la obtención de un derecho, a saber, la posibilidad de explotar un recurso natural no renovable". ${ }^{38}$ En el desarrollo del caso, la Corte establece que las regalías representan aquello que el Estado recibe por el hecho de conceder el derecho de explotar recursos naturales no renovables de los cuáles es titular. Enfatiza su análisis en el carácter limitado de los recursos naturales no renovables y los separa de los impuestos, al considerar que estos "son cargas económicas que se imponen a los particulares con el fin de financiar los gastos generales del Estado, por lo cual estas obligaciones surgen del poder impositivo del Estado". ${ }^{39}$ Si bien la Corte utiliza el término ingreso para definir la regalía minera, es clara su posición al reconocer el recurso del que proviene, y enfatiza en el supuesto de que no se recurre al poder tributario para su obtención.

Me adhiero a esa tendencia ya que dentro de los recursos patrimoniales originarios de un Estado se encuentran los recursos naturales no renovables, entre ellos los yacimiento mineros. Es necesario resaltar que, a pesar de la titularidad de dominio estatal sobre los recursos minerales, no siempre son los Estados quienes los explotan, sino que limitan su derecho de propiedad, y mediante concesiones -u otro tipo de figura- otorgan a particulares el derecho de explotación para que terceros se encarguen de esta labor. A cambio de aquello los Estados reciben un monto que se convierte en ingresos públicos, reservándose el ente estatal el poder regulatorio y de control.

Defino la regalía como una contraprestación ${ }^{40}$ exigible a un tercero en virtud del ejercicio del derecho de uso y/o disfrute que concede el titular de un bien a aquel; o, de manera similar, como un pago que se realiza por concepto de compensación al ti-

minera a la minería del Cobre”. Biblioteca del Congreso Nacional, Dpto. de Estudios, Extensión y Publicaciones No. 280 (2003). Disponible en «www.bcn.cl/pags/publicaciones/serie_estudios/esolis/nro280/nro280.html).

37. Pablo Valderrama, ibíd.

38. Corte Constitucional de Colombia. Sentencia C-027 de 2000.

39. Ibíd.

40. Contraprestación es: "La prestación a la cual se obligan recíprocamente cada una de las partes en un contrato bilateral". Pedro Flores Polo, Diccionario Jurídico Fundamental, 2a. ed. (Lima: Grijley, 2002), 174. La prestación dependerá del tipo de obligación a la que se comprometan las partes. 
tular de un bien por el hecho de abstenerse de usar y/o disfrutar una cosa que es de su propiedad. Dependiendo del instrumento jurídico en el que conste plasmada la obligación de pago de regalías, las partes pueden acordar la forma en la que el titular del bien participe de los ingresos. Si la ley no ordena otra cosa, las partes podrán decidir el porcentaje del pago, así como la forma de hacerlo, ya sea en dinerario o en especies.

Por otra parte, en el análisis precedente de la clasificación de recursos derivados tributarios, de manera controvertida se hizo alusión a las regalías al sector público como una especie de tributo. Quienes así la entienden encuentra sustento bajo el sistema de dominio regalista o regaliano, mediante el cual se conocía como regalías a las retribuciones, como un privilegio o tributo, que se debía al rey. ${ }^{41}$ De esta lectura se desprende que la antiguamente denominada regalía es lo que, según Del Barco Carrillo, hoy se debería conocer como tributo. De aceptar esa postura, se aplicaría a la regalía minera/tributo los principios tributarios, y sería relevante entonces analizar el hecho generador y los demás elementos que originarían la obligación tributaria en sí.

Belaunde, quien analiza la legislación peruana, considera que la regalía minera, al contar con todas las características de un gravamen tributario con administración delegada al SUNAT, "es un tributo así la ley pretenda darle nominalmente una naturaleza distinta, en razón de que las instituciones legales deben ser interpretadas conforme a su naturaleza real más allá de su definición presunta o virtual". ${ }^{42}$

A pesar de la aceptación acerca de que la regalía minera consiste en una erogación que se realiza al Estado, no existe una posición clara en referencia a su naturaleza fiscal. El argumento que lleva a pensar que la regalía minera es un tributo deviene del hecho de que su cobro está establecido en la ley; por lo que, si bien los ingresos que se obtienen de la exploración, explotación y comercialización de los minerales provienen de recursos naturales no renovables que se encuentran en la clasificación de recursos patrimoniales originarios, la exigencia legal ocasiona que se los asimile con tributos. Para desvirtuar dicho argumento y demostrar que la naturaleza fiscal de la regalía minera es contra-prestacional, resulta pertinente hacer una mención especial a las regalías de origen legal.

41. Del Barco Carrillo, Tributación minera, 31-2.

42. Martín Belaunde Moreyra, Derecho minero y concesión, 2a. ed. (Lima: San Marcos, 2007), 203. 


\section{REGALÍAS DE ORIGEN LEGAL}

Ciertas legislaciones ${ }^{43}$ determinan el pago de regalías al Estado como consecuencia de la explotación de recursos minerales, y esta instrumentación de la obligación -con origen legal- ha llevado a la confusión de la regalía con un tributo. Esta confusión, que en la práctica genera serias controversias, merece una reflexión especial, por lo que a continuación se hace referencia a las similitudes y diferencias entre las regalías de origen legal y los tributos.

Resulta evidente que los tributos son una forma de prestación patrimonial de carácter público exigida de manera coactiva a toda persona natural o jurídica que cumpla con los supuestos de hecho establecidos en la ley. No obstante, de acuerdo con Troya, "a más de los tributos, existen otros instrumentos que producen en la economía de los particulares similares efectos que la detracción tributaria". ${ }^{44}$

Esta afirmación resulta ser acertada, ya que, como se mencionó, el Estado puede recurrir al poder tributario, a la explotación de sus recursos naturales no renovables, o a otros recursos públicos que le permiten obtener ingresos de los particulares. Más allá de la diversidad de fuentes de ingresos, la cita también permite entender que el hecho de que exista un pago (obligatorio) de un particular a favor del Estado no constituye una cualidad exclusiva del derecho tributario.

Por otra parte, desde una visión holística del derecho financiero, De la Guerra define al tributo como "aquella prestación exigida por el Estado en ejercicio de su poder tributario y de su potestad impositiva, con fuerza obligatoria, cuyo objeto es aportar al sostenimiento del Estado y a la satisfacción de necesidades a través del gasto público, lo cual conlleva a la transformación de los recursos privados en recursos públicos" ${ }^{45}$ (énfasis de la autora).

Esta definición permite demarcar la diferencia entre una regalía -cuyo beneficiario es el Estado en su calidad de titular de un bien- y un tributo. Para imponer tributos el Estado debe hacer uso de su poder tributario, entendido como "la facultad del Estado por virtud del cual puede imponer a los particulares la obligación de aportar una

43. Bolivia, Constitución Política del Estado Plurinacional de Bolivia (2009), tercera parte, tít. II, cap. segundo, "Recursos naturales", art. 348-358; Chile, Constitución de Política de la República de Chile (1980), cap. tercero, "De los derechos y derechos constituciones", art. 19, numeral 24; Perú, Constitución de la República del Perú (1993), art. 66.

44. José Vicente Troya Jaramillo, Manual de Derecho tributario (Quito: Corporación de Estudios y Publicaciones, 2014), 4 .

45. Eddy De la Guerra, El rol de los ingresos tributarios en las finanzas públicas ecuatorianas (Quito: Corporación de Estudios y Publicaciones, 2013), 64. 
parte de su riqueza para el ejercicio de las atribuciones que le están encomendadas". ${ }^{46}$ Mientras que para establecer una regalía será necesario que el Estado recurra a sus recursos patrimoniales originarios para que, asumiendo la calidad de titular de un bien y cumpliendo con otra potestad derivada de la ley, otorgue a un tercero un derecho de uso y/o de disfrute, y, de manera correlativa, exija una compensación por la limitación que sufre en el derecho de dominio del bien.

La clasificación que realiza la doctrina generalmente aceptada de los tributos, y que es recogida por la Constitución del Ecuador, los divide en impuestos, tasas y contribuciones especiales. Para llegar a esta clasificación varios autores ${ }^{47}$ han resaltado los elementos constitutivos de cada clase de tributo. A base de esos elementos, se realizará una comparación con la regalía de origen legal cuyo beneficiario es el Estado, para identificar los rasgos diferenciadores respecto de cada una de las categorías de tributos.

Con relación al impuesto, según Troya, las posiciones de los autores Pérez de Ayala, González, Villegas y de Micheli coinciden sustancialmente en su definición, mencionando que:

Las expresiones que utilizan estos autores, son en su orden: prestación no condicionada por una actividad administrativa particular y concreta; hechos imponibles ajenos a toda actividad estatal relativa al obligado; y, prestación debida sin ninguna relación específica con una particular actividad del ente público y menos a favor del sujeto mismo que está obligado cumplirla. ${ }^{48}$

Por lo tanto, se reafirma la diferencia que existe entre una regalía y un impuesto, en razón de que, bajo la primera figura, un tercero se ve compelido al pago porque recibe un beneficio (el uso o el goce) de un bien del que es titular el Estado, mientras que, por la naturaleza del impuesto, se exige una prestación patrimonial solamente por el mandato de la ley, sin que exista una prestación estatal a favor del contribuyente. Por supuesto, la prestación ausente en este esquema es la concesión a favor de un particular por la que se le otorga el derecho de uso y explotación de los recursos mineros.

A consideración de Giuliani Fonrouge, "los impuestos son prestaciones en dinero o especies exigidas por el Estado en virtud del poder de imperio a quienes se hallen en las situaciones consideradas por la ley como hechos imponibles". ${ }^{49}$ De esta definición se debe resaltar el poder de imperio que tiene el Estado para exigir el cumplimiento de

46. Francisco de la Garza, Derecho financiero mexicano (México: Porrúa, 2006), 207.

47. Véase en Troya Jaramillo, Manual de Derecho tributario.

48. Ibíd., 24; Valdés Costa, Curso de Derecho tributario, 141.

49. Carlos Giuliani Fonrouge, Derecho financiero, vol. I (Buenos Aires: Depalma, 1983), 291. 
la obligación tributaria, así como la forma en la que se puede extinguir la obligación. El autor menciona que la prestación puede ser en dinero o especies, siendo el dinero la forma comúnmente aceptada de cumplir con esta prestación; no obstante, la posibilidad de que se lo haga en especie dependerá de la legislación interna de cada país. Acerca de la regalía existe coincidencia en la forma de extinguir la obligación -en dinero o especie-, así como las limitaciones que se pueden imponer mediante ley. Sin embargo, la naturaleza de la obligación varia en razón de que, para la configuración de una regalía, debe estar presente la voluntad de las partes, especialmente aquella proveniente del sujeto privado, que por su naturaleza está ausente en la relación legal de origen tributario.

Con relación a la tasa,${ }^{50}$ para autores como García Novoa es un tributo que tiene como presupuesto la prestación de un servicio, pero es una obligación legal y no una contraprestación que solo se refiere a obligaciones contractuales..$^{51}$ En el mismo sentido, Troya sostiene que las tasas "consisten en prestaciones que cobra el Estado unilateralmente sin que se requiera necesariamente el consentimiento del particular". ${ }^{52}$

Parte de la doctrina rechaza la idea de la tasa como contraprestación ya que para su cobro se exige por un mandato de ley -ex lege-, y no por la concurrencia de voluntades entre el administrado y el Estado - ex contratum-. El Estado no puede acordar con todos sus administrados los términos de la prestación de un servicio que por mandato normativo le compete. Tampoco puede obligar a un administrado a utilizarlo; sin embargo, para que el cobro de la tasa sea exigible, a pesar de que el servicio no sea utilizado por los ciudadanos, debe existir el mismo y ser efectivamente prestado. En este sentido, la cuantificación de la base imponible y la aplicación de la tarifa no se encuentran relacionados con criterios de equivalencia en la cantidad o calidad de la prestación, sino que, para exigir el pago, debe haberse simplemente puesto el servicio a disposición del contribuyente.

La tasa difiere de una regalía en virtud de que la primera se exige por mandato legal sin que medie la voluntad de la persona a quien se pone a disposición un servicio público. Para justificar el cobro de la regalía, a más de requerirse el cumplimiento de parámetros legales, a cambio es necesario concertar la forma de utilización del bien y se deben ejercer los derechos de uso y disfrute de manera efectiva, no solo potencial. El ejercicio de estos derechos debe darse de manera efectiva, porque a raíz de la naturaleza contra-prestacional de la regalía, este ejercicio es necesario para poder

50. Troya Jaramillo, Manual de Derecho tributario, 28. La tasa es "el tributo que mayor dificultad presenta respecto de su naturaleza", por lo que al no ser el tema de este estudio, se presentarán solo los rasgos diferenciadores más relevantes.

51. César García Novoa, El concepto de tributo (Lima: Tax Editor, 2009), 289.

52. Troya Jaramillo, Manual de Derecho tributario, 29-30. 
cuantificar el importe que será cancelado de forma equivalente al beneficio que recibe el que usa o se aprovecha el bien. A pesar de las dificultades que entraña el analizar la figura de la tasa, mediante las concepciones esbozadas, se reafirman suficientes características disímiles entre tasa y regalía como para poder concluir que pertenecen a distintas categorías en el ámbito jurídico.

La contribución especial aparece en la tercera categoría de la clasificación de los tributos, y se encuentra desarrollada en varias legislaciones. Giannini, citado por De la Garza, sostiene que:

El tributo especial es una prestación debida: a) Por quienes encontrándose en una determinada situación, experimentan una particular ventaja económica por efecto del desarrollo de una actividad administrativa, frente a todos los demás a quienes la propia actividad beneficia de modo indistinto, o bien, b) por quienes, como consecuencia de las cosas que poseen o del ejercicio de una industria, de un comercio o de otra actividad, provocan un gasto o un aumento de gasto en el ente público. ${ }^{53}$

Para la configuración de esta especie de tributo el administrado debe beneficiarse de la actividad estatal. En conexión con esta aparente inacción del administrado, el autor Ataliba manifiesta que la razón por la que el Estado tiene derecho a exigir el cobro de la contribución es por el hecho de que "el propietario en nada contribuye para la obra -que genera valorización- no es justo que se apropie de ese beneficio específico". ${ }^{54}$ Atendiendo a un criterio de justicia, la exigibilidad de la contribución especial se produce en razón del beneficio para el particular que se genera de manera indirecta por una actividad cuyo fin es de interés general. La doctrina reconoce dos tipos de contribuciones especiales, una de gastos y una de mejoras. ${ }^{55}$

Por su parte, en la regalía no existe una actividad estatal por la que se vea beneficiada la persona que tiene el derecho de uso y disfrute del bien, sino que, por el contrario, el particular debe realizar erogaciones al Estado a consecuencia de la actividad que desarrolla y los ingresos que percibe. Principalmente, el Estado presta en este esquema un servicio extraordinario, y a su vez los administrados tienen como única obligación el pago de un valor determinado (aproximadamente a prorrata del beneficio recibido). Correlativamente, está ausente cualquier otra obligación del administrado, como la de explotación de recursos naturales, por lo que la asimilación entre las dos figuras resulta imposible.

53. Francisco de la Garza, Derecho financiero mexicano, 18a. ed. (México: Porrúa, 1944), 344.

54. Geraldo Ataliba, Hipótesis de incidencia tributaria (Montevideo: Fundación Cultura Universitaria, 1977 ), 191.

55. De la Garza, Derecho financiero mexicano, 344. 
Analizados los tres tipos de tributos y sus características, se afirma que la regalía no es asimilable a ninguna figura tributaria. Si bien a consecuencia de los tributos y el pago de regalías se exigen prestaciones patrimoniales, los tributos se imponen legalmente por el poder tributario, mientras que en el caso de una regalía debe haber una concurrencia de voluntades por el que se acuerde el pago de una contraprestación o compensación a consecuencia de una limitación en la propiedad de un bien. El poder de crear, modificar y suprimir tributos le compete de manera exclusiva y unilateral al Estado, sin que medie acuerdo con los obligados al pago. Una vez creados los tributos por decisión de los representantes del pueblo, los ciudadanos se ven compelidos al pago de manera coactiva.

De manera diametralmente opuesta encontramos la regalía, ya que es necesario que la persona que desee hacer uso o aprovecharse de un bien de titular estatal debe acordar con el dueño del bien la forma de hacerlo. En este sentido debe haber concurrencia de voluntades entre las partes contratantes, respetando en todo momento lo que determina el ordenamiento jurídico interno de cada Estado. Es verdad que la legislación ecuatoriana tiende a limitar el ámbito de actuación de los contratantes, establecimiento, por ejemplo, porcentajes máximos o mínimos por el cobro de regalías; no obstante, en caso de no estar de acuerdo con esas regulaciones, las partes pueden desistir del negocio, hecho que no es permitido con los tributos.

Otro punto que merece la pena ser analizado es que, configurada la relación jurídico tributaria en virtud de las facultades otorgadas al Estado en su calidad de acreedor, no existe un tratamiento equitativo ni igualitario con relación al contribuyente. La autora Simone menciona que "sin duda en el accionar del Estado en su fase administrativa, este tiene una prerrogativas que hace difícil que la relación sea al menos equitativa entre las partes de la relación jurídico tributaria". ${ }^{56} \mathrm{Si}$ bien la doctrina afirma que la relación entre Estado y contribuyente es una relación jurídica y no de poder, la autora considera que "pese a que existen múltiples garantías a favor de los administrados, aún hoy resulta innegable la existencia de una suerte de superioridad del Estado, que imposibilita el hablar de equidad en la relación jurídico tributaria". ${ }^{57}$

Por otra parte, en la configuración de la relación que da lugar al cobro de una regalía, se habla de acuerdos en donde las partes, independientemente de si se encuentran reguladas por el derecho público o privado, buscan una verdadera relación entre iguales, o, al menos, de menor desigualdad que una relación típica tributaria. Esto tiene sentido si se analizan los intereses de las partes. El Estado, al menos en

56. Carmen Amalia Simone, "La equidad tributaria en el Ecuador" (ponencia, XI Jornadas Ecuatorianas de Derecho Tributario. Quito, diciembre 2010).

57. Ibíd., 18. 
las fases iniciales de una operación que resulte en el pago de regalías, está llamado a invitar la inversión de un tercero, y en tal medida puede verse compelido a otorgar ciertas facilidades, diferentes a la pura imposición de su poder en el ámbito tributario. Esto, claro está, sin renunciar a sus potestades y atribuciones. Otros ejemplos de este comportamiento estatal se plasman en los Tratados Bilaterales de Inversión, en razón de que mediante su suscripción se busca limitar las potestades de los Estados para otorgar seguridad al inversionista de uno de los Estados contratantes.

El hecho de que el pago de regalías esté regulado como obligatorio en el ordenamiento jurídico, no transforma su naturaleza contra-prestacional o ex contractum. Esta circunstancia regula el ámbito de las negociaciones y las actuaciones de las partes; no obstante, es necesario resaltar que no limita el derecho del titular del bien de negociar las facultades que de este se desprenden, así como las de un tercero en búsqueda del aprovechamiento de estas. Todos los acuerdos a los que arriben las partes deberán plasmarse en contratos con las estipulaciones específicas, respetando lo que mande la ley.

\section{REGULACIÓN DE LA REGALÍA MINERA EN ECUADOR}

En el análisis del ordenamiento jurídico ecuatoriano, se inicia con el cuerpo normativo más extenso que ha tenido el Ecuador en tema de derechos, tanto de las personas como de la naturaleza: la Constitución de la República de $2008 .^{58}$ En ella se dispone que el Estado central tendrá competencia exclusiva sobre recursos minerales, (art. 261, 11) y que los recursos naturales no renovables son de propiedad inalienable, imprescriptible e inembargable del Estado. No obstante, se permite que el sector privado coparticipe de los beneficios de su aprovechamiento, siempre que el monto que se entregue al Estado no sea inferior al monto que recibe la empresa. Tanto si la explotación es realizada por el Estado, o por particulares, la Constitución ordena que deben cumplir con los principios ambientales ${ }^{59}$ ahí establecidos (art. 408).

58. Antes de su adopción, fue promulgado por la Asamblea Constituyente, el 18 de abril de 2008, el Mandato Constituyente No. 6 para extinguir, sin compensación económica, todas las concesiones mineras que en la fase de exploración no hayan realizado ninguna inversión en el desarrollo del proyecto al 31 de diciembre de 2007, las que no hayan presentado un estudio de impacto ambiental y las que no hayan realizado los procesos de consulta previa, entre otras. A su vez se declaró la caducidad de las concesiones mineras que no hayan cancelado las patentes de conservación.

59. La Constitución en este apartado hace referencia a principios medioambientales en los que subyace una visión antropocéntrica, demostrando una colación con los principios ecológicos que surge de una visión biocéntrica y que no permitían su explotación. 
A través de normativa secundaria, como la Ley de Minería, la Ley reformatoria para la Ley de Equidad Tributaria del Ecuador, la Ley Orgánica de Régimen Tributario Interno y el Código Orgánico de Ordenamiento Territorial y Administración Descentralizada se ha dispuesto que la coparticipación de los particulares se realice mediante el pago de tributos, regalías, patentes y utilidades laborales atribuibles al Estado.

La Ley de Minería ${ }^{60}$ establece que se podrá excepcionalmente delegar la participación en el sector minero a través de concesiones (art. 30). La concesión minera es "un acto jurídico, por el cual el Estado transmite al sujeto de derecho privado, sus potestades para la utilización de la riqueza minera. La concesión es pues, la autorización que otorga el Estado para el aprovechamiento de la riqueza minera, bajo determinadas condiciones preestablecidas en la ley" ${ }^{11}$ Su naturaleza es mixta ya que es necesario un contrato donde se manifieste la voluntad del concesionario de recibir la concesión -hecho que no se contempla en la teoría del acto unilateral-; al tratarse de un bien de dominio público, se requiere la autorización de la Administración -se otorga solamente en el caso que el particular cumpla con los requisitos legales-; y porque al momento de celebrarse el contrato ambas partes - a pesar de las facultades de la administracióndeben someterse a lo establecido en él y en la ley.

La Ley de Minería clasifica a los minerales en metálicos, no metálicos, y áridos y pétreos. Es competencia exclusiva de los Gobiernos Autónomos Descentralizados regular a los últimos, por lo que la normativa aplicable para ellos está prevista en el Código Orgánico de Ordenamiento Territorial y Administración Descentralizada y las ordenanzas respectivas.

En lo concerniente a la explotación de yacimientos mineros, la Ley prevé que puede desarrollarse mediante la modalidad de Contrato de Servicios Profesionales o a través de un Contrato de Explotación Minera. En la primera modalidad el prestatario minero recibe como contraprestación a su encargo el pago de un honorario y es el Estado quien asume el riesgo de la operación. Por el contrario, en la segunda modalidad, es el concesionario quien extrae los recursos minerales bajo su cuenta y riesgo, se apropia de los recursos extraídos, y debe cancelar al Estado regalías mineras por dicha apropiación.

En el segundo escenario, una vez que existe la resolución que declara el inicio de la etapa de explotación minera, el concesionario debe suscribir con el Estado un contrato de explotación, en el cual se estipulan los términos, condiciones y plazos contractua-

60. Ley de Minería, en Registro Oficial No. 145.

61. Derecho de Minería, Gases e Hidrocarburos. Disponible en «http://distancia.upla.edu.pe/libros/derecho/09/DERE CHO_DE_MINERIA_GASES_E_HIDROCARBUROS.pdf $\rangle$. 
les. En referencia al monto a pagar por concepto de regalías, en el mismo artículo se menciona que el Estado podrá acordar con los concesionarios mineros el pago de rentas y regalías generados por el aprovechamiento de minerales metálicos, con el producto refinado de su explotación (art. 41); en caso de ser otra la forma de pago, las regalías se establecen a base de un porcentaje sobre la venta del mineral principal y de los minerales secundarios, y los montos por concepto de regalías deberán estar debidamente reflejados en los informes semestrales de producción y en las declaraciones presentadas al Servicio de Rentas Internas (art. 92).

La ley dispone que el porcentaje por concepto de regalías se calcule sobre la venta del mineral principal y los minerales secundarios, siendo no menor al 5\% sobre las ventas y, para el caso del oro, cobre y plata, no mayor al $8 \%$. El porcentaje de regalía para la explotación de minerales no metálicos y materiales de construcción se calcula con base en los costos de producción. La evasión del pago de regalías será causal de caducidad, sin perjuicio de los efectos civiles y penales a que diere lugar (art. 93). La Disposición General Tercera establece que el porcentaje correspondiente al Estado por concepto de regalías será recaudado a través del Servicio de Rentas Internas, el cual estará investido de todas las facultades y atribuciones que le otorga la normativa tributaria vigente.

De las normas mencionadas se puede apreciar que la ley prevé que el pago de la regalía minera se acuerde en el contrato de explotación minera, considerándose un recurso patrimonial originario en donde debe existir un concierto de voluntades; a su vez, establece la forma de calcular el porcentaje de la regalía. Se hace alusión a declaraciones al Servicio de Rentas Internas, se sanciona al concesionario en caso de evasión de pago con la caducidad del contrato, y le inviste al Servicio de Rentas Internas de todas sus facultades para que la recaude, asimilándola a un tributo. Por lo tanto se evidencia que en la legislación ecuatoriano existe una confusión entre estos recursos públicos.

Se podría entender que exista un formulario de declaración al SRI, pero solamente en cuanto este funcione como un ente de coordinación que ayuda al Estado central en el cobro de las regalías; sin embargo, de acuerdo al art. 89 del Código Tributario, la declaración es la forma en que el sujeto pasivo procede a determinar el tributo. Esta consideración, más la utilización del término evasión, asimila la regalía con un tributo. Si bien la norma es expresa en sancionar la evasión de pago con la caducidad del contrato, la utilización del término evadir consiste en reducir o eliminar el pago de impuestos.

Giuliani Fonrouge, en su análisis del ilícito tributario, menciona que evasión equivale a "todo acto u omisión que violando disposiciones legales, en el ámbito de un país o en la esfera internacional, produce la eliminación o la disminución de la carga 
fiscal". ${ }^{62}$ En Ecuador la evasión es una forma de defraudación tributación sancionada por el Código Tributario y el Código Orgánico Integral Penal.

Por lo tanto, si bien se podría deducir que el no pago de regalías mineras tiene como consecuencia la caducidad del contrato, no obstante la evasión -con su connotación tributaria- conlleva un análisis más profundo del hecho dañoso, que bajo la doctrina del derecho penal tributario entrañaría dolo al querer engañar a la Administración. Si se califica el no pago de la regalía como evasión fiscal, la responsabilidad para el incumplido es mucho mayor que el simple incumplimiento de una obligación convencional.

El SRI, a pesar de no ser una autoridad en materia minera, ${ }^{63}$ de acuerdo a la Ley de Minería se encuentra habilitado para hacer uso de todas sus facultades. Resulta sumamente cuestionable este hecho ya que la recaudación de la regalía minera, al no ser un tributo, mal puede atribuírsele a un ente que no es especialista en la materia, más aún con todas las facultades específicas que ostenta, las cuales son aplicables solamente para materia tributaria. Es importante resaltar que la facultad determinadora es exclusiva de las administraciones tributarias, por lo que, mediante su atribución, se la diferencia del resto de actividades que realizan la otras instituciones públicas, y solo se aplica para tributos.

En el ámbito presupuestario el desconocer la verdadera naturaleza de la regalía minera acarrea que existan errores en la asignación de los ingresos que se prevén y el monto máximo de gastos que se aprueba. Se deben respetar las partidas presupuestarias que han sido asignadas y la disposición constitucional de que los egresos permanentes se financian con ingresos permanentes. Por lo tanto, una regalía minera debe consignarse bajo los ingresos que provienen de los recursos patrimoniales del Estado y no del poder tributario, por lo que con ellas, por ejemplo, no se deben pagar suelos de funcionarios públicos.

El conocer la verdadera naturaleza de la regalía minera permite no solo un mejor desarrollo normativo y procesal, sino que también es importante en el ámbito presupuestario. Para ello es necesario que las personas que realicen el Presupuesto General del Estado conozcan en profundidad temas como recursos, ingresos y gastos públicos. La correcta asignación de los ingresos según su naturaleza debe direccionar también su asignación correlativa en los gastos, asunto no menor, si es que finalmente

62. Carlos Giuliani Fonrouge, Derecho financiero, vol. II (Buenos Aires: Depalma, 1984), 637.

63. Las autoridades en materia minera son el Ministerio Coordinador de Sectores Estratégicos, el Ministerio de Recursos No Renovables, la Agencia de Control Minero, la ENAMI, y el Instituto Nacional de Investigación Geológico, Minero y Metalúrgico. 
la minería a gran escala se desarrolla en Ecuador, y los ingresos por regalías pasan a representar una porción significativa en el presupuesto general del Estado.

A más de lo expuesto, el conflicto de mayor importancia en lo referente al régimen fiscal de la regalía minera es el determinar la vía de solución de controversias, la normativa aplicable y la autoridad que debe resolverlas.

La confusión de considerarla como tributo generaría la interrogante de si se debe acudir primero ante instancias administrativas del SRI, posteriormente ante el Tribunal Contencioso Tributario y si la normativa aplicable sería la tributaria. De considerar que fuere de naturaleza tributaria, en el caso de inversión extranjera, también deberían analizarse los Tratados Bilaterales de Inversión con relación a las cláusulas de estabilización tributaria, en donde los porcentajes por concepto de regalía no podrían modificarse. De igual forma para las cláusulas de resolución de controversia que estipulan arbitraje, en donde la obligación tributaria no puede ser resuelta mediante este método.

De acuerdo a su naturaleza, el Estado tiene derecho a recibir una compensación por la limitación que sufre a su derecho de dominio de los recursos naturales no renovables, en este caso minero. Por lo tanto, de suscitarse controversias se deberá estar a lo estipulado en el contrato, que, si se somete a la jurisdicción de jueces ecuatorianos, requerirá previsiblemente acudir a las instancias administrativas en materia minera, $\mathrm{y}$ posteriomente al Tribunal Contencioso Administrativo.

El resolver el conflicto acerca de la vía de solución de controversias, la normativa aplicable y la autoridad competente, depende de identificar con claridad la naturaleza jurídica de la regalía minera. Así, con normativa clara, que no se preste para confusiones entre regalía y tributo, el primer paso que hay que realizar es remitirse al contrato de concesión minera. En el supuesto de que exista cláusula arbitral, o cláusula especial para la resolución de controversias, en este escenario se deberá estar a lo pactado en ella. El hecho de que la regalía minera no tenga naturaleza tributaria permite que los efectos de la obligación sea arbitrable.

Así también, entendido el pago de la regalía minera como una obligación contractual, que se suscribe al tenor de la ley, en el supuesto de que el porcentaje se modifique a consecuencia de una fluctuación repentina de los precios de los minerales o externalidades del mercado, las partes podrían exigir una renegociación contractual a consecuencia de la teoría de la desproporción contractual.

Los argumentos que anteceden sirven para demostrar que la categorización de la regalía en el mundo jurídico es mucho más que un tema semántico o puramente doctrinario. Esa clasificación, técnicamente hecha, tiene efectos profundos en cuanto al aprovechamiento de la regalía y su tratamiento fiscal. En último término, el eliminar la ambigüedad es siempre un mecanismo esencial para la preservación de la seguridad jurídica. 


\section{CONCLUSIONES}

La investigación realizada en torno a la naturaleza jurídica de la regalía minera en Ecuador permite concluir que en el desarrollo normativo de dicha figura, tanto en Ecuador como en otros países, existe confusión entre tributo y regalía. Esta errónea asimilación genera que se susciten un sinnúmero de conflictos jurídicos y prácticos.

Si bien esta investigación ha permitido demostrar que la naturaleza jurídica de la regalía minera, desde un análisis doctrinario profundo, corresponde a una naturaleza contra-prestacional que solamente se produce en el caso de existir un acuerdo de voluntades entre el titular de dominio de los recursos minerales -el Estado- y un tercero al que se le otorga el derecho de beneficiarse de la utilización; aún existe confusión de esta figura con un tributo. Como consecuencia del acuerdo (ausente en la relación tributaria) mediante el cual se limita el derecho de uso del Estado, surge la obligación del tercero de pagar una suma de dinero o entregar en especies el porcentaje que le corresponde al titular del derecho de propiedad.

La regalía es una contraprestación exigible a un tercero en virtud del ejercicio del derecho de uso y/o disfrute que concede el titular de un bien a aquel; o, de manera similar, es una contraprestación exigible de carácter compensatorio que merece el titular de un bien por el hecho de abstenerse de usar y/o disfrutar una cosa que es de su propiedad. En el caso específico de la regalía minera, esta consiste en la erogación económica o en especie, que debe cancelar el titular de un derecho minero al Estado, en calidad de compensación, como una consecuencia de la contraprestación que recibe al beneficiarse de la actividad minera y que el Estado le permite hacerlo. Este concepto debería ser adoptado por la legislación ecuatoriana, para que, a partir de aquel, se desarrollen postulados normativos claros y adecuados para la materia.

En el ordenamiento jurídico ecuatoriano se identifica la figura de la regalía minera; sin embargo, no hay una aclaración explícita del recurso público al que recurre el Estado y al cual se adscribe. Esto supone la aparente coexistencia de las dos conceptualizaciones de la regalía minera (contraprestacional-tributaria) que resultan incompatibles entre sí puesto que cada una nace de diversos recursos públicos. Esta confusión genera su incorrecta regulación en el ordenamiento jurídico, así como diferentes efectos perjudiciales tanto para la administración como para el administrado.

La regalía minera, entendida tanto como tributo o como contraprestación por la que se exige un pago a consecuencia de la suscripción del contrato, representa un ingreso público potencial y consiste en una erogación que se realizará al Estado. No obstante, mientras que la obligación de pago de un tributo surge solamente a consecuencia del cumplimiento de un mandato legal, la obligación de pago de una contraprestación se produce como resultado de la celebración de un contrato, por lo que la relación entre el Estado y el particular se rige por una normativa distinta a la del derecho tributario. 
Para el caso de regalías de origen legal y los tributos, la diferenciación fundamental radica que en el caso de la primera el Estado recurre a sus recursos patrimoniales originarios, para que, asumiendo la calidad de titular de un bien y cumpliendo con otra potestad derivada de la ley, otorgue a un tercero un derecho de uso y/o de disfrute, $\mathrm{y}$, de manera correlativa, exija una compensación por la limitación que sufre en el derecho de dominio del bien, mientras que, para imponer tributos, el Estado debe hacer uso de su poder tributario. En el caso de la regalía debe haber una concurrencia de voluntades por el que se acuerde el pago de una contraprestación o compensación a consecuencia de una limitación en la propiedad de un bien, respetando en todo momento lo que determina el ordenamiento jurídico interno de cada Estado.

Otro punto que merece la pena ser resaltado es que, configurada la relación jurídico tributaria, en virtud de las facultades otorgadas al Estado en su calidad de acreedor, no existe un tratamiento equitativo ni igualitario con relación al contribuyente. Mientras que configurada la relación que da lugar al cobro de una regalía se habla de acuerdos en donde las partes, independientemente de si se encuentran reguladas por el derecho público o privado, buscan una verdadera relación entre iguales, o, al menos, de menor desigualdad que una relación típica tributaria.

Es importante recalcar el hecho de que el pago de una regalía se ordene conforme a lo establecido en ley; no puede confundirse con el poder impositivo del Estado con relación a los tributos. Como se ha comentado a lo largo de este análisis, si bien los dos consisten en prestaciones patrimoniales que se pagan al Estado, quien debe pagar una regalía minera lo hace porque voluntariamente se coloca en una posición de hacerlo a consecuencia de solicitar que se le otorgue una concesión minera. El pago de una regalía tiene un origen de carácter contractual. Si bien ambas partes deben dar cumplimiento a la ley -como todo ciudadano sometido a un Estado de Derecho y en cualquier relación contractual de objeto lícito-, en este supuesto existe un consenso previo que se plasma a través de cláusulas que gobiernan la nueva relación jurídica, pudiendo variar para cada caso en concreto.

Las inconsistencias normativas en Ecuador se dan respecto de normas de ámbito nacional y seccional. La falta de técnica legislativa y el empleo de términos de ámbito tributario respecto de la regalía hacen difícil definir el alcance de las consecuencias jurídicas asignables a sujetos obligados al pago.

Finalmente, el asignar un carácter definitivo y explícito a la regalía minera tiene alcances cruciales para la actividad minera. Esto permite definir claramente la autoridad de control, dilucidar la competencia exclusiva para dirimir conflictos con los concesionarios, someter diferendos a la jurisdicción arbitral, y evaluar de manera certera la responsabilidad asociada al ejercicio de dicha actividad. En suma, es un paso necesario en el esfuerzo nacional de lograr que la minería sea un pilar más determinante en el desarrollo, así como para cumplir con el derecho y principio de la seguridad jurídica. 


\section{BIBLIOGRAFÍA}

Ahumada, Guillermo. Tratado de finanzas públicas, t. I, 4a. ed. Buenos Aires: Plus Ultra, 1968.

Ataliba, Geraldo. Hipótesis de incidencia tributaria. Montevideo: Fundación Cultura Universitaria, 1977.

Belaunde Moreyra, Martín. Derecho minero y concesión, 2a. ed. Lima: San Marcos, 2007.

Bustamante, Teodoro, y Rommel Lara Ponce, coord. "El Dorado o la caja de Pandora: matices para pensar la minería en Ecuador”. En Cuadernos de trabajo. Quito: FLACSO, 2010.

Del Barco Carrillo, Víctor. Tributación minera. La Paz: Azul Editores, 2006.

De la Garza, Francisco. Derecho financiero mexicano. México: Porrúa, 2006.

De la Guerra, Eddy. El rol de los ingresos tributarios en las finanzas públicas ecuatorianas. Quito: Corporación de Estudios y Publicaciones, 2013.

Falcón Tella, Ramón. Derecho financiero y tributario (parte general). Madrid: Universidad Complutense de Madrid, 2013.

García Novoa, César. El concepto de tributo. Lima: Tax Editor S.A., 2009.

Giuliani Fonrouge, Carlos. Derecho financiero, vol. 1, 3a. ed. Buenos Aires: Depalma, 1983.

---. Derecho financiero, vol. II. Buenos Aires: Depalma, 1984.

González-Berti, Luis. Compendio de derecho minero venezolano: Legislación sobre hidrocarburos. Mérida: Gráficos Universitarios, 1960.

Jarach, Dino. Finanzas públicas y Derecho tributario, 3a. ed. Buenos Aires: Abeledo Perrot, 1996.

Lima de Moura, Guilherme. "La administración de los bienes minerales como fuerza motriz del desarrollo social”. Foro: Revista de Derecho. No. 21 (2014).

Martino Mendiluce, Fernando. Diccionario de conceptos económicos y financieros. Santiago de Chile: Andrés Bello, 2001.

Marzorato, Osvaldo. Derecho de los negocios internacionales. Buenos Aires: Astrea, 1991.

Parada, Ramón. Derecho Administrativo III: Bienes públicos; Derecho urbanístico. Madrid: Marcial Pons, 2013.

Sanjinés, Claudio. Curso de Derecho minero: introducción al estudio de la legislación comparada. La Paz: Imprenta Artística, 1940.

Simone, Carmen Amalia. "La equidad tributaria en el Ecuador”. Ponencia, XI Jornadas Ecuatorianas de Derecho Tributario. Quito, diciembre 2010.

---. Régimen tributario de la minería en el Ecuador. Material inédito. Quito, 2014.

Troya, José Vicente. "De la actividad financiera y las ciencias que ellas tratan”. En Manual de Derecho tributario. Quito: Documento actualizado a agosto 2011, versión digital sin publicar, 1997. 
---. "Los tributos y sus clases". En Derecho internacional tributario. Quito: Corporación Editora Nacional, 1990.

Valderrama, Pablo. "En torno al debate sobre la aplicación de un royalty o renta minera a la minería del Cobre". Biblioteca del Congreso Nacional, Dpto. de Estudios, Extensión y Publicaciones, No. 280 (2003). Disponible en «www.bcn.cl/pags/publicaciones/serie_estudios/esolis/nro280/nro280.html〉.

Valdés Costa, Ramón. Curso de Derecho tributario. Bogotá: Depalma/Temis/Marcial Pons, 1996.

Vergara, Blanco Antonio. Instituciones de Derecho minero. Santiago: Abeledo Perrot, 2010.

Vildósala, Jorge. El dominio minero y el sistema concesional en América Latina y el Caribe. Venezuela: Editorial Latina C.A., 1999.

Villegas, Héctor. Manual de finanzas públicas. Buenos Aires: Depalma, 2000.

\section{OTros}

Asamblea Constituyente del Ecuador. Mandato Constituyente No. 6. Registro Oficial, Suplemento, No. 321, 22 de abril de 2008.

Bolivia, Constitución Política del Estado Plurinacional de Bolivia. 2009.

Brasil, Constitución de la República Federativa de Brasil. 1998.

Chile, Constitución Política de la República de Chile. 1980.

Corte Constitucional de Colombia. Sentencia C-027 de 2000. M.P. Alejandro Martínez Caballero.

Declaración de Río+20 de la Conferencia de las Naciones Unidas sobre el Desarrollo Sostenible, 2012.

Ecuador. Código Orgánico de Ordenamiento Territorial, Autonomía y Descentralización. Registro Oficial, Suplemento, No. 303, 19 de octubre de 2010.

---. Consejo Nacional de Planificación. “Resolución No. CNP-003-2013: Plan Nacional para el Buen Vivir 2013-2017”, 24 de junio de 2013.

---. Constitución de la República del Ecuador. 2008.

---. Ley de Minería. Registro Oficial, No. 157, 29 de enero de 2009.

---. Reglamento General a la Ley de Minería. Registro Oficial, No. 67, 16 de noviembre de 2009.

Perú. Constitución de la República del Perú. 1993.

---. Ley de Regalía Minera.

---. Reglamento de la Ley de Regalía Minera.

Fecha de recepción: 9 de octubre de 2016. Fecha de aprobación: 17 de abril de 2017. 